ISSN 0819-2642

ISBN 0734026439

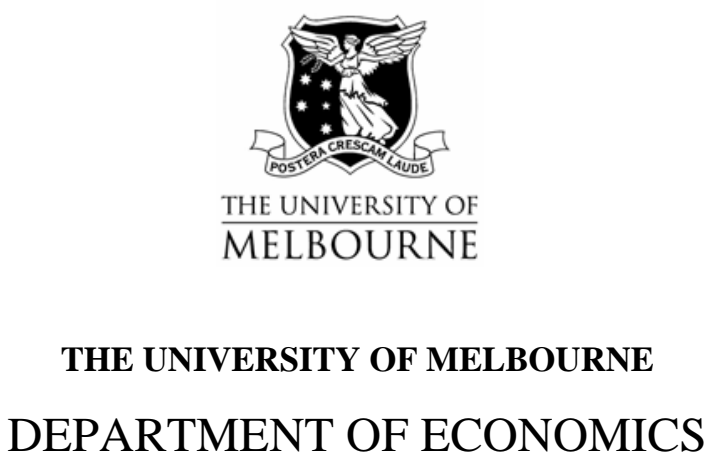

RESEARCH PAPER NUMBER 985

JANUARY 2007

\title{
Corporation Tax Buoyancy and Revenue Elasticity in the UK
}

by

John Creedy

\&

Norman Gemmell

Department of Economics The University of Melbourne Melbourne Victoria 3010 Australia. 


\title{
Corporation Tax Buoyancy and Revenue Elasticity in the UK*
}

\author{
John Creedy* and Norman Gemmell** \\ * The University of Melbourne; ** University of Nottingham
}

\begin{abstract}
Observed changes in corporation tax revenues from year to year, which include the effects of changes in tax rates, deductions and compliance, appear to be highly volatile relative to profits, the tax base. This paper examines whether the 'built-in' fiscal drag properties of corporation tax can be expected to display similar properties. Simple, conceptual modelling demonstrates that the corporate tax revenue elasticity does indeed display this property in the presence of regular cyclical fluctuation in profit growth, suggesting that much of the observed volatility is inherent to the corporation tax system.
\end{abstract}

*This research was conducted while Norman Gemmell was at HMRC's Analysis department. We are grateful to colleagues there for their support of this research, especially David Ulph and Edwin Ko. The views expressed in this paper are those of the authors and do not necessarily reflect those of HMRC. We are grateful for comments from participants at presentations at H.M. Treasury and the New Zealand Treasury and Inland Revenue Department. 


\section{Introduction}

Growth rates of corporation tax receipts in the UK are known to fluctuate widely from year to year, both absolutely and relative to profits - the main corporation tax base. ${ }^{1}$ Tax revenue authorities have found it increasingly difficult to provide reliable forecasts of corporation taxes, even when given reasonably accurate projections of profits. These revenue changes in relation to profits could reflect a combination of factors. First, there are the inherent, or 'built-in', properties of the UK corporation tax system; these are associated with 'fiscal drag'. Second, revenues are influenced by discretionary changes in tax rates, thresholds and other conditions affecting tax liability. Third, tax revenue changes can be affected by changes in avoidance and evasion.

The present paper concentrates on analysing the potential contribution of the built-in, or fiscal drag, properties of the corporation tax system in the UK. ${ }^{2}$ In particular it seeks to explain how far the observed volatility in the buoyancy of corporation tax revenues, with respect to profits, can be explained by the tax's fiscal drag properites. This is important because if relatively large changes in tax revenues, relative to profit changes, are indeed an inherent characteristic of the corporation tax system, substantial challenges are raised for tax forecasting.

The paper is structured as follows. Section 2 reports evidence relating to buoyancy in the UK over the last twenty-five years or so, demonstrating the extent of its volatility. Section 3 introduces the key concept of fiscal drag as it applies to corporation taxes. A commonly used measure of fiscal drag is

\footnotetext{
${ }^{1}$ Corporate tax revenues have also remained high despite periodic decreases in the statutory tax rate. Devereux et al. (2004) examined various empirical factors associated with the buoyant UK corporation tax revenues since 1980 and concluded that the primary explanation lies in the strong growth of financial companies' profits. In effect, this provided an expanding tax base to compensate for reductions in the statutory rate.

${ }^{2}$ Previous papers which have examined revenue aspects of the UK corporation tax include Young (1992), Basu et al. (2003), Metz and Weale (2003), and Devereux et al. (2004). The first three papers generally focus on forecasting models or methods, and none deals explicitly with fiscal drag properties. Measuring effective rates of corporation tax has also been a focus of a number of recent papers including Nicodeme (2001) and Devereux and Klemm (2003).
} 
the tax revenue elasticity. Section 4 therefore discusses the factors affecting the revenue elasticity of individual firms, along with the aggregate revenue elasticity. An important aspect of this is the corporate tax schedule. ${ }^{3}$ Section 5 therefore describes the schedule of UK corporate tax rates applicable to total profits net of deductions. This requires special attention in the corporation tax context because it differs from the type of tax function typically used in the context of personal income taxation (the main focus of previous studies of fiscal drag). Section 6 examines the likely variation in the revenue elasticity over the economic cycle. Conclusions are in section 7 .

\section{Corporation Tax Buoyancy in the UK}

Corporation tax revenues can be measured either in cash or accrual terms. The former measures the amount of tax paid by companies and received by the UK Revenue and Customs department (HMRC) in a given period, while the latter measures the corporation tax liability as assessed using the tax code during a given period (usually a fiscal year).

Using HMRC data on corporation tax accruals and profits, available on a consistent basis from 1992/93, Figure 1 shows the growth rates of tax accrual, $\mathrm{dT} / \mathrm{T}$, and gross taxable profits, $\mathrm{dP} / \mathrm{P}$, compared to GDP growth, $\mathrm{d}(\mathrm{GDP}) / \mathrm{GDP}^{4}{ }^{4}$ This demonstrates the much greater variability in gross profit growth compared with GDP growth rates. Furthermore, although both corporation tax accruals and profits are relatively volatile, their growth rates follow quite different patterns. This latter feature contributes substantially to highly volatile corporation tax buoyancy in Figure 2.

Tax buoyancy is measured as the growth in tax revenues (receipts or ac-

\footnotetext{
${ }^{3}$ The term shedule is used here to refer to the form of the tax function, rather than the source of income. Tax regulations are expressed in terms of a 'schedular' structure, where each source or schedule has its own rules. Indeed the UK system is complicated by the fact that the different sources allow or disallow particular profit off-sets or tax credits, depending on the source of the profit (such as UK trading profits, foreign-sourced profits, and profits from property transactions).

${ }^{4}$ These HMRC profit data relate only to company profit as declared for tax purposes and therefore treats all company gross losses as zero profits. They are therefore quite different from profits in companies' commercial accounts which include both positive profits and losses.
} 
cruals) divided by the growth in profits or GDP. Figure 2 shows the accrualsbased buoyancy measure (with respect to GDP and profits) and compares this with a receipts-based measure. ${ }^{5}$ Corporation tax accruals are derived directly from the HMRC measure of gross profits liable to UK tax, so this provides a more consistent denominator for the accruals-based buoyancy measure (from 1992/93). The buoyancy of corporation tax receipts can be examined over a longer period by using the Office of National Statistics measure of profits the gross operating surplus of financial and non-financial companies (denoted $\mathrm{F}+\mathrm{NF}$ GOS). ${ }^{6}$ This is also shown in Figure 2.

It can be seen that accrual buoyancy with respect to GDP varies approximately within the range -5 to +5 , where +5 implies that tax grew five times as fast as GDP. However, negative buoyancy values can arise either because GDP growth is negative or because tax growth is negative, but not both. If both are negative, a positive buoyancy value results. Receipts and accruals buoyancy can be seen to be quite different, at least on an annual basis. This reflects the different profit series used in the denominator of each measure and the impact of timing differences between corporation tax receipts and accruals. ${ }^{7}$ The large negative values arise in years of negative profit growth which are not sufficiently large or sustained to produce negative tax growth. However, unusually large negative profit growth of almost -4 per cent in 2001-02 led to a fall in tax accruals for that year such that accruals buoyancy remained positive. Large positive or negative buoyancy values tend to arise when annual GDP or profit growth is close to zero, so that the small denominator generates a high buoyancy value.

\footnotetext{
${ }^{5}$ The accruals-based measure of profits used here is the HMRC measure of gross taxable trading profits and other taxable income and net capital gains; see http://www.hmrc.gov.uk/stats/corporate_tax/table11_2.pdf. Corporate tax accrual is also available from this source.

${ }^{6}$ Constructing receipts buoyancy measures using economy-wide gross operating surplus (GOS) yields similar evidence of volatility though peaks and troughs often do not coincide. Economy-wide GOS includes F+NF GOS as well as the gross operating surplus of households, non-profit institutions (serving households) and general government.

${ }^{7}$ Corporation tax in the UK can be paid either in advance or in arrears of a company's assessed liability. Hence, tax receipts and accruals rarely match exactly in a given fiscal year and can sometimes vary markedly. For example, in 1999 when the Quarterly Instalment Payment (QIPs) system was introduced, receipts exceeded accruals by around 25 per cent as both current and some future liabilities had to be paid.
} 


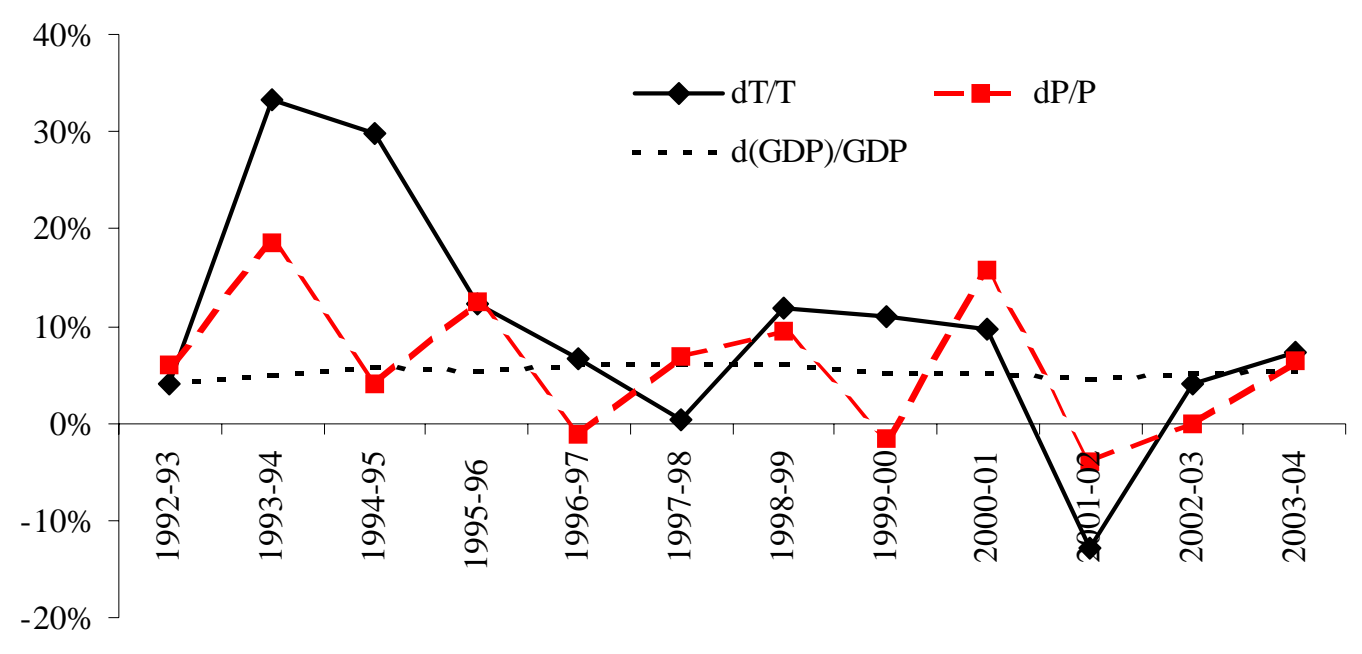

Figure 1: Corporation Tax, Profit and GDP Growth Rates

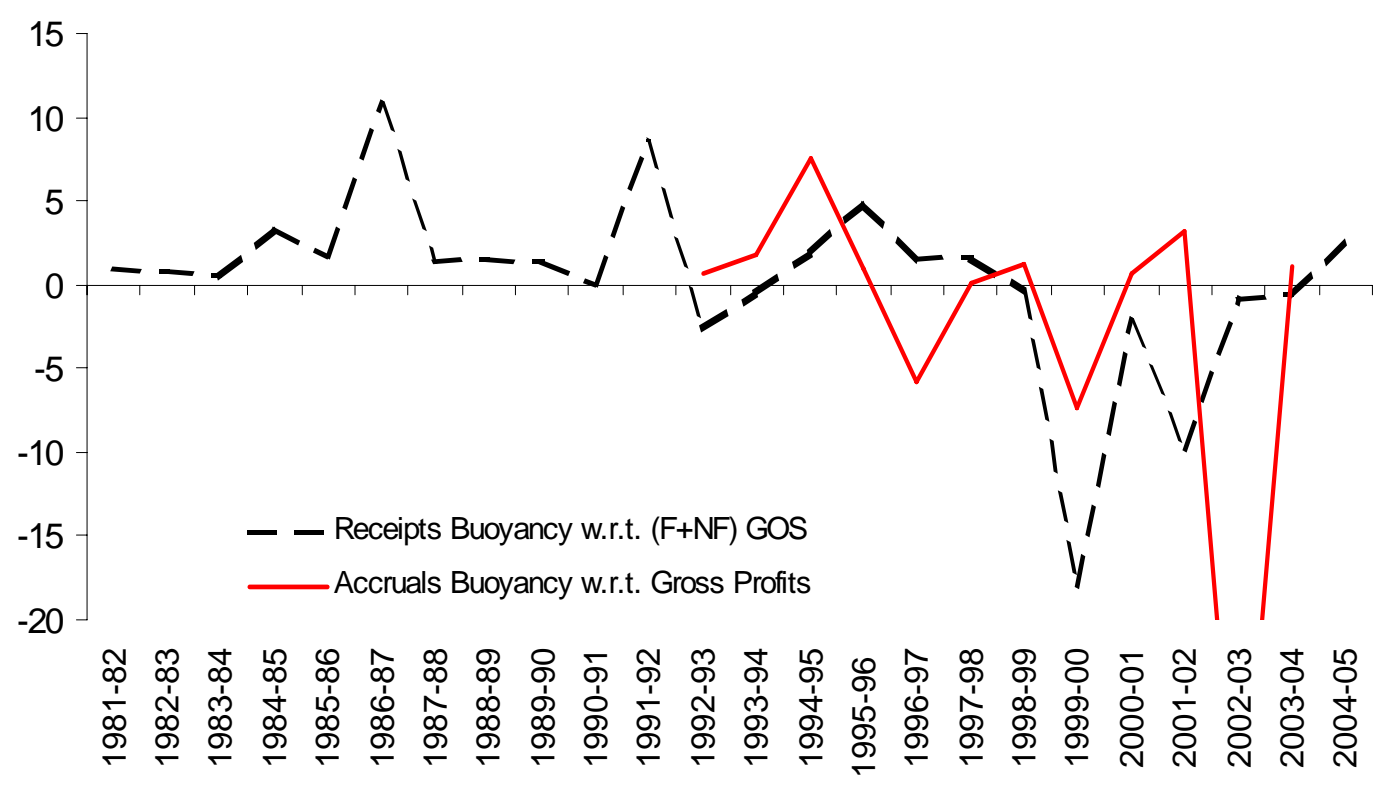

Figure 2: Corporation Tax Buoyancy 
The tax buoyancy observed in Figure 2 could result from a number of factors. First, the built-in flexibility, or fiscal drag, properties of the tax structure generate automatic changes in revenues as the tax base changes. Second, revenues can be affected by discretionary changes in tax rates or other tax parameters. Third, changes in revenue can be influenced by changes in compliance effort or efficiency of collection. Although there have been numerous discretionary changes to the corporation tax regime in the UK over the period examined here, and possibly changes in corporation tax compliance of unknown magnitude, it would be surprising if these factors could substantially account for the observed volatility in corporation tax buoyancy. This raises the question of whether fiscal drag, as captured by the tax revenue elasticity, can explain the observed buoyancy volatility. The following sections examine how far modelling of this revenue elasticity is capable of generating such volatility. ${ }^{8}$

\section{Corporation Tax Buoyancy and Fiscal Drag}

Fiscal drag is a familiar feature of income taxes where the existence of fixed or income-related tax allowances, and rising marginal tax rates generate a rising share of total income paid in income tax as average incomes rise. Fiscal drag is therefore a common feature of progressive taxes. It can be measured in unit-free terms by the revenue elasticity of a tax - the automatic percentage increase in tax revenues divided by the percentage increase in the tax base. For progressive taxes this elasticity exceeds one, as revenues rise proportionately faster than the tax base.

Despite numerous studies of the fiscal drag properties of personal income and, to a lesser extent, indirect taxes, there is very little existing analysis of corporation tax fiscal drag. ${ }^{9}$ This may reflect, in part, a view that there is

\footnotetext{
${ }^{8}$ This paper concentrates on the conceptual aspects of the corporation tax revenue elasticity. In Creedy and Gemmell (2006b), a microsimulation model is developed and applied to HMRC data to demonstrate the empirical contribution of fiscal drag to the buoyancy of UK corporation tax.

${ }^{9}$ For surveys of, and contributions to, the literature on fiscal drag of income and indirect taxes, see Creedy and Gemmell (2002a, b; 2004; 2006a), Heinemann (2001).
} 
less normative significance to a tax that leads to companies with larger profits paying proportionately more tax, compared to a tax where individuals or households with higher personal incomes pay proportionately more tax. Secondly, where most corporation tax revenues are paid by companies at a single rate, fiscal drag is often presumed to be of little quantitative significance.

In the UK, there are two non-zero corporation tax rates: 19 per cent and 30 per cent. ${ }^{10}$ However, the lower, 'small company rate' of 19 per cent is levied on companies with net taxable profits (that is, profits after all deductions) below $£ 1.5$ million. ${ }^{11}$ It therefore contributes only a small fraction of total revenue raised, the remainder being collected at the 30 per cent rate. Increasing company profits, which push companies across the net profit threshold when they begin to pay tax at the 30 per cent rate, are therefore unlikely to be an important contributor to the overall fiscal drag properties of the UK corporation tax system.

However, UK corporation tax has two features which could contribute importantly to fiscal drag. Firstly various deductions, allowable against profits, or in the form of tax credits, mean that about 60 per cent of gross profit declared for tax purposes is tax-free. Thus for a typical company, the marginal tax rate on profit is higher than its average tax rate. This generates fiscal drag. Secondly, profits either before or after deductions can be negative, but negative profits (losses) are not eligible for a tax refund. Though various deductions (for example, group relief) provide a form of tax refund on some losses, this is not sufficient to ensure that the effective refund on a given loss is equal to the effective tax on an equivalent amount of profit.

Finally, this section has used terms such as profits, deductions and tax base without defining them precisely. In the remainder of this paper, the corporation tax base is defined as 'gross (taxable) profits'; that is gross profits defined for tax purposes - total profits declared to HMRC as potentially liable to corporation tax. This is distinct from the accounting definition of gross profits where some items of income or expenditure in company accounts are

\footnotetext{
${ }^{10}$ This simple summary conceals the complexity of the structure, which is described in more detail in section 5 .

${ }^{11}$ Even this value exaggerates the importance of the $19 \%$ rate since, for companies in groups, the $£ 1.5$ million threshold is split between all the companies in the group.
} 
treated differently (for example, interest payments and capital expenditure). Net (taxable) profits are gross (taxable) profits minus all deductions, where deductions are defined as all tax allowances claimed in the form of profit off-sets (for example, capital allowances) plus the profit off-set equivalents of tax credits (for example, double taxation relief). Corporation tax liability is therefore obtained by multiplying the relevant corporation tax rate by net profits.

\section{The Corporation Tax Revenue Elasticity}

This section examines the basic characteristics of the corporate tax revenue elasticity as it applies to an individual company and all companies combined. Subsection 4.1 introduces the revenue elasticity in the context of a single company. The role played by deductions is considered further in Subsection 4.2. Subsection 4.3 considers aggregation over all firms.

\subsection{Revenue Elasticity for Individual Companies}

Consider a single company. Gross profits are $P$ and total deductions are $D$, so that net profits, $P^{T}$, are:

$$
P^{T}=P-D
$$

Suppose, for simplicity, that there is a single tax rate of $t$. Hence when $P^{T}>0$, the tax liability, $T(P)$, is:

$$
T(P)=t(P-D)
$$

and when $P^{T} \leq 0, T(P)=0$. The tax revenue elasticity, $\eta_{T, P}$, for the company is defined as the proportional increase in tax divided by the proportional increase in gross profits, so that:

$$
\eta_{T, P}=\frac{d T / T}{d P / P}=\frac{d T}{d P} \frac{P}{T}
$$

The elasticity is thus the ratio of the marginal to the average tax rate. From (2), the average tax rate is given by:

$$
A T R=\frac{T(P)}{P}=\frac{t(P-D)}{P}
$$


while the marginal tax rate is:

$$
M T R=\frac{d T(P)}{d P}=t\left(1-\frac{d D}{d P}\right)=t\left(1-\frac{D}{P} \eta_{D, P}\right)
$$

where $\eta_{D, P}$ is the elasticity of deductions with respect to gross profits. Hence it follows that:

$$
\begin{aligned}
\eta_{T, P} & =\frac{1-\frac{D}{P} \eta_{D, P}}{1-\frac{D}{P}} \\
& =\left(1-\frac{d D}{d P}\right)\left(\frac{P}{P-D}\right)
\end{aligned}
$$

Equation (6) shows that, for a taxpaying company (for which $P-D>0$ ), the second term in brackets exceeds unity if $D>0$, but since $d D / d P \lesseqgtr 0$, the first term is ambiguously signed. Thus the size and sign of both the level of deductions relative to net or gross profits, $D / P$ (recalling that $P=P^{T}+D$ ), and the change in deductions relative to gross profits, $d D / d P$, are crucial determinants of the revenue elasticity. If deductions are independent of gross profits, then $\eta_{D, P}=0$, and the revenue elasticity takes the simpler form:

$$
\eta_{T, P}=\frac{P}{P-D}
$$

In this case the revenue elasticity is simply the ratio of gross to net taxable profit. For companies with positive but very low tax liabilities, that is $P-D$ is small, the elasticity is large, and higher profits reduce the elasticity towards unity. For companies with a zero tax liability (that is, where $P-D \leq 0$ ), the revenue elasticity is zero.

Figure 3 illustrates this case. The profile, $\mathrm{WXX}^{\prime} \mathrm{Y}$, shows the revenue elasticity as profit increases. Along the range WX, profit increases from zero or negative values towards $P=D$, and the elasticity remains zero. At $P=D$ the elasticity becomes infinitely large because the denominator in equation (7) is zero. Beyond this point, over the range $\mathrm{X}^{\prime} \mathrm{Y}$, the elasticity declines asymptotically towards unity as $P$ increases further. 


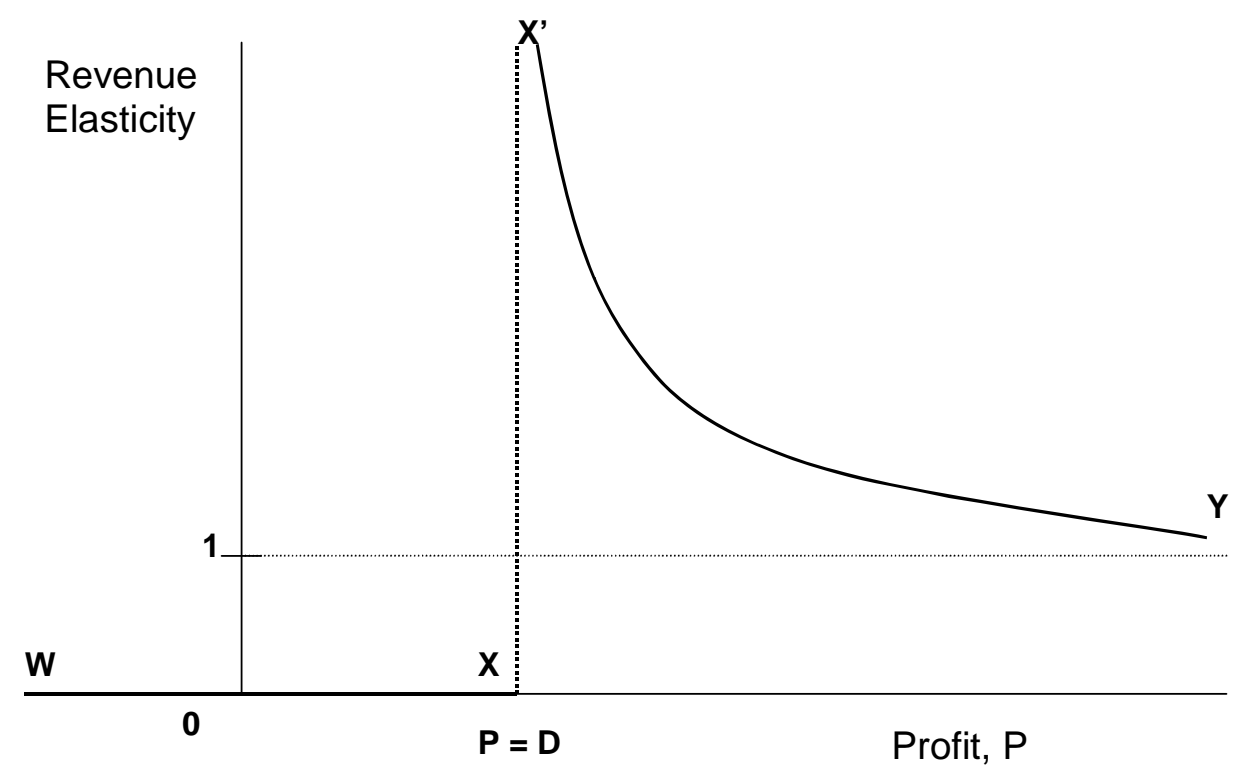

Figure 3: Individual Revenue Elasticity

\subsection{Revenue Elasticity with Endogenous Deductions}

In general the elasticity of deductions with respect to gross profits, $\eta_{D, P}$, is non-zero and its behaviour has an important impact on revenue elasticities, as seen from equation (6). Deductions available to be claimed depend, for example, on investment, via capital allowances, and on past profits and losses of the company. In the case of a company within a group, deductions also depend on group members' profits and losses. This subsection considers the effects of these on the revenue elasticity.

To the extent that deductions are mainly composed of capital allowances, and investment expenditure rises with profits, this tends to increase deductions (with a lag), so that $d D / d P>0$. On the other hand, losses would be expected to fall as profits rise, so that $d D / d P>0$ is more likely. Defining capital allowances and losses claimed against profits, as $C A$ and $L C$ respectively, consider two extreme cases. First, a given level of $D$ is made up entirely of capital allowances, so that $D=C A$, and second, the same level of $D$ is composed entirely of losses claimed, so that $D=L C$. For a given 
level of profits, the term $\frac{P}{P-D}$ in (6) is the same for both cases and is greater than 1.

If investment is positively correlated with profits, then $d D / d P>0$ for capital allowances, whereas $d D / d P<0$ for losses. For illustration, let $d C A / d P=\varepsilon$ and $d L C / d P=-\varepsilon$. Thus the first term in brackets in (6) becomes $1-\varepsilon$ for capital allowances, but $1+\varepsilon$ for losses. That is, losses contribute to the revenue elasticity exceeding 1 (recalling that $\frac{P}{P-D}>1$ ), whereas capital allowances encourage a revenue elasticity less than 1 . It becomes less than 1 if $1-\varepsilon$ outweighs $\frac{P}{P-D}$ in (6). Of course, both deductions also have 'level' effects which raise the elasticity, since greater deduction levels imply larger values of $\frac{P}{P-D}$.

\subsubsection{Group Relief}

It is readily shown that the availability of group relief (compared with no group relief deductions or single firms only) leads to higher revenue elasticities for companies which remain taxpayers, and zero elasticities for previous taxpayers whose liabilities are reduced to zero. Consider, for example, the case of two firms, $i$ and $j$, where $i$ is in profit while $j$ makes a loss. In the absence of group relief, or for single companies, the elasticity of firm $j$ is zero, while while $j$ 's elasticity exceeds unity depending on the value of net profits, $P_{i}-D_{i}$.

Suppose group relief becomes available, or the two companies form a group. Firm $j$ is able to transfer some or all of it's losses to its partner. In this case $j$ 's elasticity remains zero, but deductions for the profit-maker have increased by the value of transferred losses. Firm $i$ 's elasticity therefore increases - the denominator in equation (4) falls. In terms of Figure 3 , the profit-maker's schedule $\mathrm{WXX}^{\prime} \mathrm{Y}$ shifts rightwards by the amount of transferred losses, $D_{2}-D_{1}$; this is shown in Figure 4 .

At each gross profit, in excess of the new deductions level, $D_{2}$, for firm $i$, the revenue elasticity is greater than previously. However, for companies which are removed from taxpaying status as a result of group relief (those between $D_{1}$ and $D_{2}$ ), the revenue elasticity falls to zero. The effect of group relief on the revenue elasticity therefore depends on the relative sizes of the 


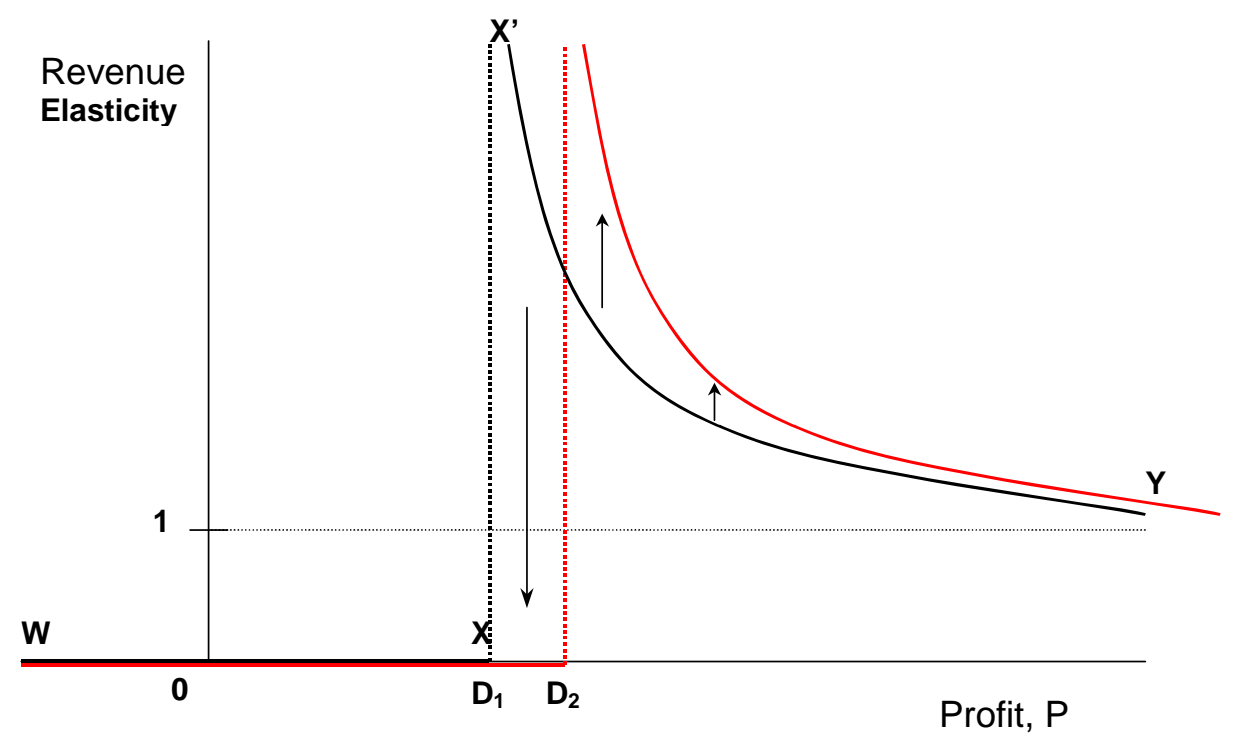

Figure 4: Elasticity with Varying Deductions

positive profits and group-relieved losses within the group. However, in a subsequent period, if the previously loss-making firm were to become a taxpayer, it would not have access to its previous losses as a profit off-set. Hence its revenue elasticity would be lower than it would be without the use of group relief - in terms of Figure 4 it would be further to the right.

This result also demonstrates the impact on the elasticity of companies amalgamating to form groups. Amalgamation will cause the revenue elasticity to increase for those profit-making group members which remain taxpayers, compared with their previous single status. However, for previous profit-making companies whose profits are now eliminated by transferred losses, the elasticity falls to zero. The elasticities of previous loss-making companies are unaffected by amalgamation - they remain zero. Again, however, their future elasticities are also affected by the surrender of their current losses. 


\subsubsection{Consolidated Accounting}

A move to consolidated accounting whereby group, rather than company, profits form the tax base, would have a similar effect to group relief. However, consolidation would effectively allow some losses, which remain 'stranded' under the current UK group relief system, to be deducted from group profits. In terms of Figure 4 this implies a greater rightward shift of the elasticity profile compared with the group relief case. Thus a greater range of positive profits would yield a zero revenue elasticity, but the elasticities associated with the higher tax-liable profit levels would increase. This should not be confused with the fact that, for given profit levels, tax levels are lower with consolidation. Rather, the higher revenue elasticity for taxpaying groups, with consolidation, implies that revenues grow faster relative to profits, than previously. Hence, faster tax growth is gained at the cost of lower initial tax levels (unless other tax parameters are changed).

\subsubsection{Cyclical Effects}

Figures 3 and 4 are less useful to illustrate the impact on revenue elasticities of economic booms and recessions, when deductions are expected to respond to cyclical changes in profits. An economic downturn is typically associated both with declining profits in taxpaying firms and greater losses among lossmakers. Where losses dominate deductions, $d D / d P<0$ is more likely, and equation (6) showed the impact on the firm's revenue elasticity if it remains a taxpayer. Of course, cyclical fluctuations can also be expected to shift some firms into and out of taxpaying status. Clearly, how gross profits and deduction change over the economic cycle is crucial for the value of the revenue elasticity both of individual firms, and of firms in aggregate. This is explored further in Section 6. First, the next sections considers the determinants of the corporation tax revenue elasticity aggregated across all firms, and the role of the corporation tax schedule. 


\subsection{The Aggregate Revenue Elasticity}

For governments interested in raising revenues, the major policy concern is typically with the behaviour of aggregate, rather than individual firms', tax revenue. A corresponding aggregate revenue elasticity can be defined as follows. Let $P=\sum_{i=1}^{n} P_{i}$ and $T=\sum_{i=1}^{n} T_{i}$ denote aggregate profits and aggregate revenue, where there are $i=1 \ldots n$ firms. The change in total tax revenue is therefore:

$$
d T=\sum_{i=1}^{n} \frac{d T_{i}}{d P_{i}} d P_{i}
$$

Defining the aggregate revenue elasticity as $\eta=\frac{d T}{d P} \frac{P}{T}$, it can be shown from (8) that the aggregate revenue elasticity is:

$$
\eta=\sum_{i=1}^{n}\left(\eta_{T_{i}, P_{i}}\right)\left(\eta_{P_{i}, P}\right)\left(\frac{T_{i}}{T}\right)
$$

where $\eta_{T_{i}, P_{i}}$ is the elasticity for an individual firm, $T_{i} / T$ is the share of firm $i$ 's tax payments in total tax revenue, and $\eta_{P_{i}, P}$ is the elasticity of the each firm's profits with respect to total profits. This last elasticity depends on changes in the distribution of profits. It would be equal to 1 if all profits were to change in equal proportions. However, this is not typically the case, with profit growth rates often quite different across firms; indeed it is common for some firms to move into loss whilst others move in the opposite direction. As a result, profit dynamics can be expected to be important for estimates of aggregate revenue elasticities, and the aggregate revenue elasticity is not amenable to tractable analytical solutions. ${ }^{12}$

\section{The Corporation Tax Schedule and Rev- enue Elasticities}

For an individual firm, the tax revenue elasticity, $\eta_{T, P}$, in equation (6) has been defined above as:

$$
\eta_{T, P}=\frac{d T}{d P} \frac{P}{T}=\frac{M T R}{A T R}
$$

\footnotetext{
${ }^{12}$ It is examined using simulation methods in Creedy and Gemmell (2006b).
} 
where $M T R$ and $A T R$ are the marginal and average tax rates (defined with respect to gross profit) facing the firm - and referred to below as the Gross $M T R$ and ATR. Since the UK corporation tax 'schedule' describes the relationship between tax liabilities and net, rather than gross, profits, it is useful to decompose this elasticity into two components. Hence:

$$
\eta_{T, P}=\left(\eta_{T, P^{T}}\right)\left(\eta_{P^{T}, P}\right)
$$

Equation (11) expresses $\eta_{T, P}$ as the product of the elasticity of tax paid with respect to net profits, $\eta_{T, P^{T}}$, and the elasticity of net profits to gross profits, $\eta_{P^{T}, P}$. The first component elasticity is determined by the corporation tax 'schedule'. In the UK this involves four net profit thresholds, $m_{0}, \ldots, m_{4}$, two tax rates $t_{1}$ and $t_{2}$, and two 'marginal relief fractions', $F_{1}$ and $F_{2}$. A firm's tax liability within each range is given in Table 1.

Table 1: The Corporate Tax Schedule

\begin{tabular}{ll}
\hline Profit Range & Tax \\
\hline$P^{T} \leqslant m_{0}$ & $T\left(P^{T}\right)=0$ \\
$m_{0}<P^{T} \leqslant m_{1}$ & $T\left(P^{T}\right)=t_{1} P^{T}-F_{1}\left(m_{1}-P^{T}\right)$ \\
$m_{1}<P^{T} \leqslant m_{2}$ & $T\left(P^{T}\right)=t_{1} P^{T}$ \\
$m_{2}<P^{T} \leqslant m_{3}$ & $T\left(P^{T}\right)=t_{2} P^{T}-F_{2}\left(m_{3}-P^{T}\right)$ \\
$P^{T}>m_{3}$ & $T\left(P^{T}\right)=t_{2} P^{T}$ \\
\hline
\end{tabular}

It can be seen that there are two ranges of net profit, $m_{1}<P^{T} \leqslant m_{2}$ and $P^{T}>m_{3}$ where taxation is a fixed proportion of net profit, $t_{1}$ and $t_{2}$ respectively, otherwise this proportion varies. Since the corporation tax schedule specifies the relationship between the corporation tax paid, $T$, and net profit, $P^{T}$, Net average and marginal tax rates may be defined as:

$$
\operatorname{ATR}\left(P^{T}\right)=\frac{T\left(P^{T}\right)}{P^{T}}
$$

and:

$$
\operatorname{MTR}\left(P^{T}\right)=\frac{d T}{d P^{T}}
$$

and the revenue elasticity component in $(11), \eta_{T, P^{T}}$, is simply:

$$
\eta_{T, P^{T}}=\left\{\frac{M T R\left(P^{T}\right)}{A T R\left(P^{T}\right)}\right\}
$$


The Net ATRs and MTRs associated with each net profit range in Table 1, are shown in Table 2, and illustrated in Figure 5. These are based on current UK parameter values; see Table $3 .{ }^{13}$ For example, over the range $m_{0} \leqslant P^{T} \leqslant m_{1}$ the $A T R\left(P^{T}\right)$ gradually increases from 0 to $t_{1}$, such that:

$$
\operatorname{ATR}\left(P^{T}\right)=\frac{T\left(P^{T}\right)}{P^{T}}=t_{1}-F_{1}\left(\frac{m_{1}}{P^{T}}-1\right)
$$

and $t_{1}$ is reduced by a fraction of the proportional difference between $m_{1}$ and net profit. The tax schedule obviously differs from a typical income tax schedule where, for example, a higher tax rate is applied only to income measured above the relevant threshold, and lower ranges of income are taxed at lower rates. For a firm with $P^{T}$ in excess of $m_{3}$, all of net taxable profit is subject to the higher rate of $t_{2} \cdot{ }^{14}$

Table 2: Net Average and Marginal Tax Rates

\begin{tabular}{lll}
\hline Profit Range & \multicolumn{1}{c}{$\operatorname{ATR}\left(P^{T}\right)$} & $\operatorname{MTR}\left(P^{T}\right)$ \\
\hline$P^{T} \leqslant m_{0}$ & 0 & 0 \\
$m_{0}<P^{T} \leqslant m_{1}$ & $t_{1}-F_{1}\left(\frac{m_{1}}{P^{T}}-1\right)$ & $t_{1}+F_{1}$ \\
$m_{1}<P^{T} \leqslant m_{2}$ & $t_{1}$ & $t_{1}$ \\
$m_{2}<P^{T} \leqslant m_{3}$ & $t_{2}-F_{2}\left(\frac{m_{2}}{P^{T}}-1\right)$ & $t_{2}+F_{2}$ \\
$P^{T}>m_{3}$ & $t_{2}$ & $t_{2}$ \\
\hline
\end{tabular}

These properties mean that although $T\left(P^{T}\right) / P^{T}$ is either constant or increasing, the tax schedule as a whole does not display marginal tax rate progression. ${ }^{15}$

The resulting elasticity of tax with respect to net profits, $\eta_{T, P^{T}}$, is illustrated in Figure 6. It can be seen that this elasticity is constant (and equals

\footnotetext{
${ }^{13}$ The parameter values apply to single firms where no group relief is relevant. In the case of company groups, the profit thresholds, $m_{0}$ to $m_{4}$, are divided by the number of firms in the group, and the marginal relief fractions adjusted accordingly.

${ }^{14}$ The two marginal relief fractions are determined in order to ensure that there are no discontinuities in the tax schedule. For example, $T\left(P^{T}=m_{0}\right)=0=t_{1} m_{0}-$ $F_{1}\left(m_{1}-m_{0}\right)$, so that $F_{1}=t_{1} m_{0} /\left(m_{1}-m_{0}\right)$. Similarly, $T\left(P^{T}=m_{2}\right)=t_{1} m_{2}=$ $t_{2} m_{2}-F_{2}\left(m_{3}-m_{2}\right)$, and thus $F_{2}=\left\{m_{2}\left(t_{2}-t_{1}\right)\right\} /\left(m_{3}-m_{2}\right)$.

${ }^{15}$ As Figure 5 shows, over the range $m_{0}<P^{T} \leqslant m_{1}$ the term $d T / d P^{T}=t_{1}+F_{1}$, and this falls to $t_{1}$ over the range $m_{1}<P^{T} \leqslant m_{2}$. Similarly, $d T / d P^{T}$ falls from $t_{2}+F_{2}$ over the range $m_{2}<P^{T} \leqslant m_{3}$, to $t_{2}$ when $P^{T}>m_{3}$.
} 
Table 3: Parameters of the CT Schedule: 2006

\begin{tabular}{llll}
\hline Parameter & Value & Parameter & Value \\
\hline$m_{0}$ & $10 k$ & $t_{1}$ & 0.19 \\
$m_{1}$ & $50 k$ & $t_{2}$ & 0.30 \\
$m_{2}$ & $300 k$ & $F_{1}$ & $19 / 400$ \\
$m_{3}$ & $1500 k$ & $F_{2}$ & $11 / 400$ \\
\hline
\end{tabular}

1) above $m_{3}$, and for $m_{1}<P^{T} \leqslant m_{2}$, but otherwise it varies with $P^{T}$. This component, $\eta_{T, P^{T}}$, of the overall revenue elasticity, $\eta_{T, P}$, is potentially important for understanding the revenue responsiveness of small firms since, as Figure 6 illustrates, this can vary substantially with net profit levels below $m_{3}$.

However, total corporation tax revenues are dominated by revenues from large firms, where $P^{T}>m_{3}$. For those firms, $\eta_{T, P^{T}}=1$ and the elasticity of net profit with respect to gross profit is the sole determinant of the total revenue elasticity, $\eta_{T, P}$. That is, for $P^{T}>m_{3}$ :

$$
\eta_{T, P}=\eta_{P^{T}, P}
$$

Thus, for most large firms the elasticity properties of the corporate tax are complicated not so much by the nature of the tax schedule as by the complexities involved in the transformation from $P$ to $P^{T}$. As shown in equation (6) above, this elasticity is far from straightforward, and depends on the level of, and changes in, deductions relative to net or gross profits. Section 4 argued that the ratio of deductions to profits is not in general constant but is likely to vary over the economic cycle. As a result, the tax revenue elasticity can also be expected to vary systematically over the cycle. This is the subject of the following section.

\section{The Revenue Elasticity over the Cycle}

This section considers the likely pattern of the aggregate revenue elasticity when profits cycle round a trend growth rate. Deductions against corporation tax in the UK are dominated by losses and capital allowances claimed, and 


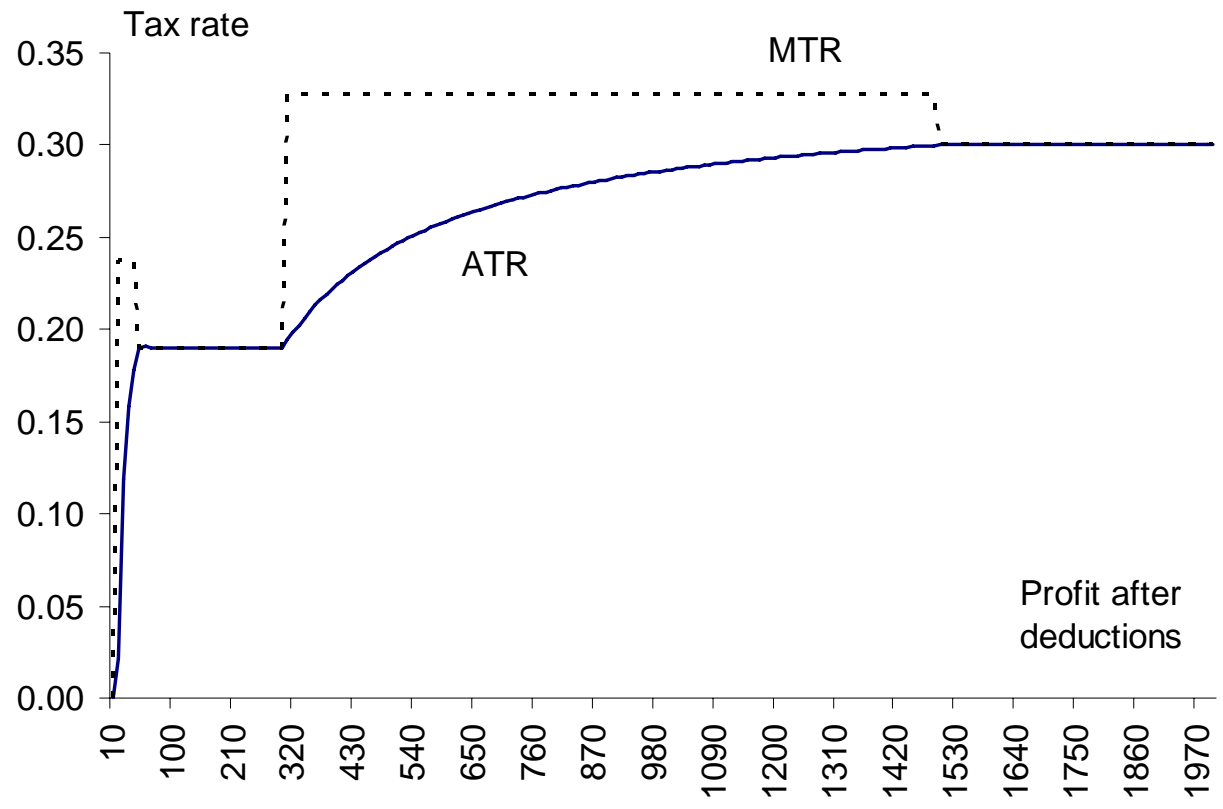

Figure 5: Marginal and Average Tax Rates

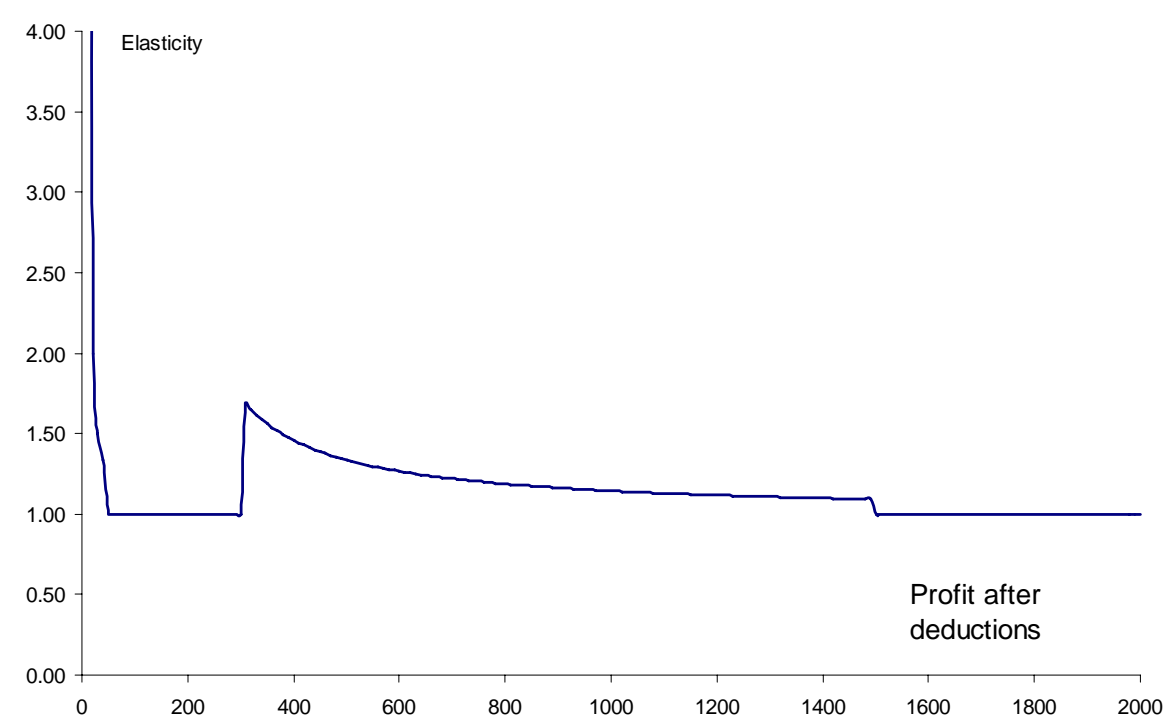

Figure 6: Revenue Elasticity of Tax with Respect to Net Profits 
these can be expected to display both trend and cyclical aspects. ${ }^{16}$ The aggregate elasticity, as given in equation (9), is a tax-share weighted average of the product of each firms' revenue elasticity and the elasticity of its profits with respect to aggregate profits. If all firms move together (so that there are no changes in relative profits among firms) the aggregate elasticity is $\eta=\sum_{i=1}^{n}\left(\eta_{T_{i}, P_{i}}\right)\left(\frac{T_{i}}{T}\right)$. In the trivial case where, for every firm, profits and deductions grow at the same rate, $d P_{i} / P_{i}=d D_{i} / D_{i}$ and the individual and aggregate revenue elasticities are all unity.

The key issue therefore is whether a steady long-run trend rate of profit growth is likely to produce the conditions under which the revenue elasticity is unity. During trend growth - though not within a cycle - it seems plausible that profits and deductions grow at similar rates. For firms which consistently make positive profits, and which therefore have no loss pools, deductions are composed of capital allowances, and it is not unreasonable to suppose that investment and profits grow at similar rates. Though for some firms the long run trend growth of profits may at some point involve net profits turning from negative to positive, the share of such firms' tax in total tax revenue is likely to be so small that they have little effect on the aggregate. Hence, over the long-run a corporate tax revenue elasticity approximately equal to one can be expected, at least in the UK where losses and capital allowances dominate deductions claimed against corporation tax.

However, within an economic cycle these conditions cannot be expected to hold, as company losses and investment vary from year to year in response to economic conditions. In those periods of the cycle which have rising profits, the growth of tax revenue is likely to be lower than that of profits since loss pools - accumulated during the previous low point of the cycle - can be deducted against profits. Conversely, when profits are in the falling stages of the cycle, those loss pools will typically have been exhausted in the previous high point, so taxation is not expected to fall as fast as profits. Hence, it is likely that aggregate tax revenue follows a smoother cycle than that of

\footnotetext{
${ }^{16}$ For example, in 2004 losses used and capital allowances accounted for over 85 per cent of all deductions claimed against corporation tax in the UK; see Inland Revenue Statistics, Table 11.2.
} 


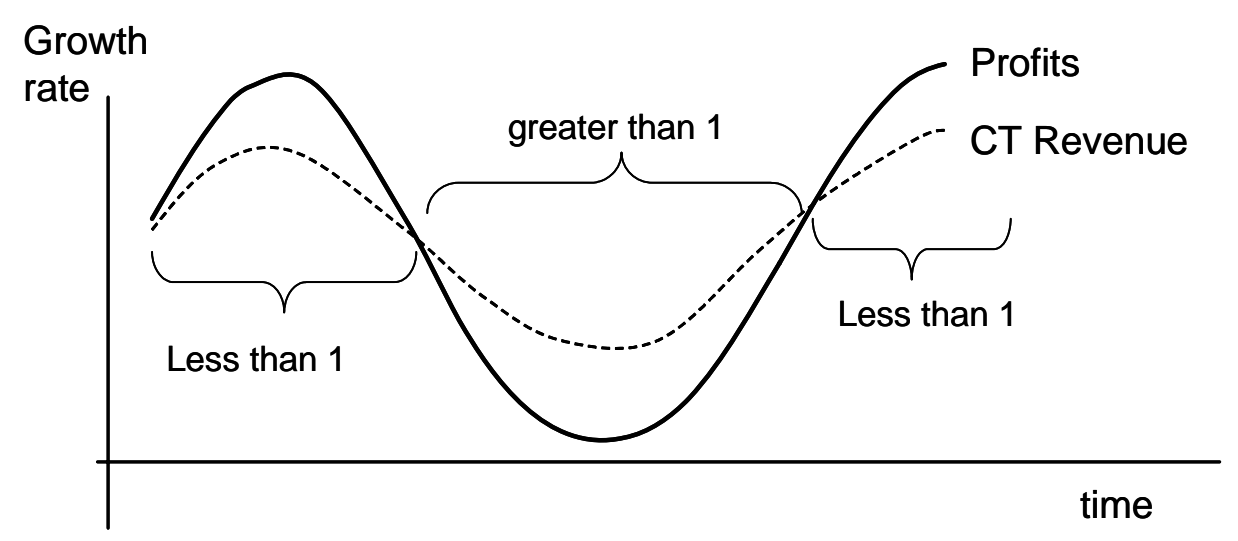

Figure 7: Moderate Cycle

profits. A key source of this smoothing effect is that, whereas companies' gross profits (as measured in company accounts, for example) can become negative, the net taxable profits on which CT liability is assessed cannot be negative. ${ }^{17}$ A simple illustrative example of this smoothing effect is provided in the Appendix, for the case of a single firm.

This cyclical pattern is shown in Figure 7 using a sine wave to depict the economic cycle for both (gross) profits and taxes, and in which profit and tax growth is always positive. As the Figure shows, profit growth above trend implies elasticity values less than one, whilst profit growth below trend implies elasticities greater than one. That is, the corporation tax revenue elasticity would appear to be counter-cyclical.

A similar cycle is depicted in Figure 8 but in this case profit growth becomes negative at the bottom of the cycle, whereas tax growth remains positive. This has a dramatic effect on the cyclical aspect of the revenue elasticity, which now exceeds one when profit growth is below trend but still positive, and the elasticity becomes negative at the bottom of the cycle when profit growth is negative. Finally, Figure 9 shows that if the cyclical downturn is sufficiently severe such that both tax and profit growth become

\footnotetext{
${ }^{17}$ Note that data on the HMRC measure of gross profits would not necessarily display this property since negative gross profits (gross losses) are recorded for tax purposes as zero gross profits. Losses appear instead as an off-set claimed against positive gross profits.
} 


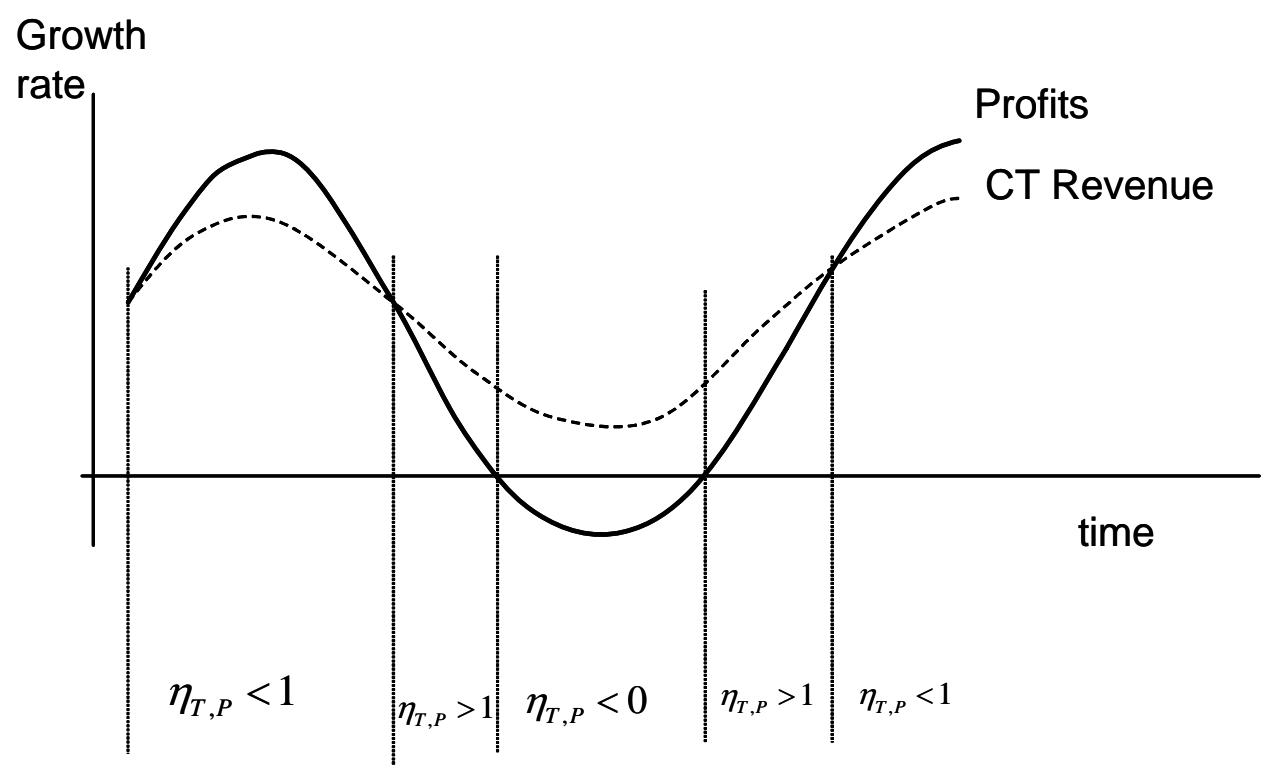

Figure 8: A Cycle with Negative Profit Growth

negative, this generates even more volatility in the revenue elasticity.

Illustrative revenue elasticity profiles for the types of cycle depicted in Figures 8 and 9 are shown in Figures 10 and 11. These are constructed using a cycle based on a sine wave with values as shown in Table 4 . The values shown are within the range of observed profit growth rates given in Figure 1, and were obtained from sine waves with an amplitude of 20 (profits) and 7 (tax) around trend growth shown in the table. A wavelength of 15 was used.

Table 4: Profit and Tax Growth Rates

\begin{tabular}{lrr}
\hline & Percentage growth rates \\
\hline Figure 10 & Profits & Taxation \\
Max & 30 & 17 \\
Min & -10 & 3 \\
Trend & 10 & 10 \\
\hline Figure 11 & & \\
Max & 25 & 12 \\
Trend & -15 & -2 \\
Trend & 5 & 5 \\
\hline
\end{tabular}




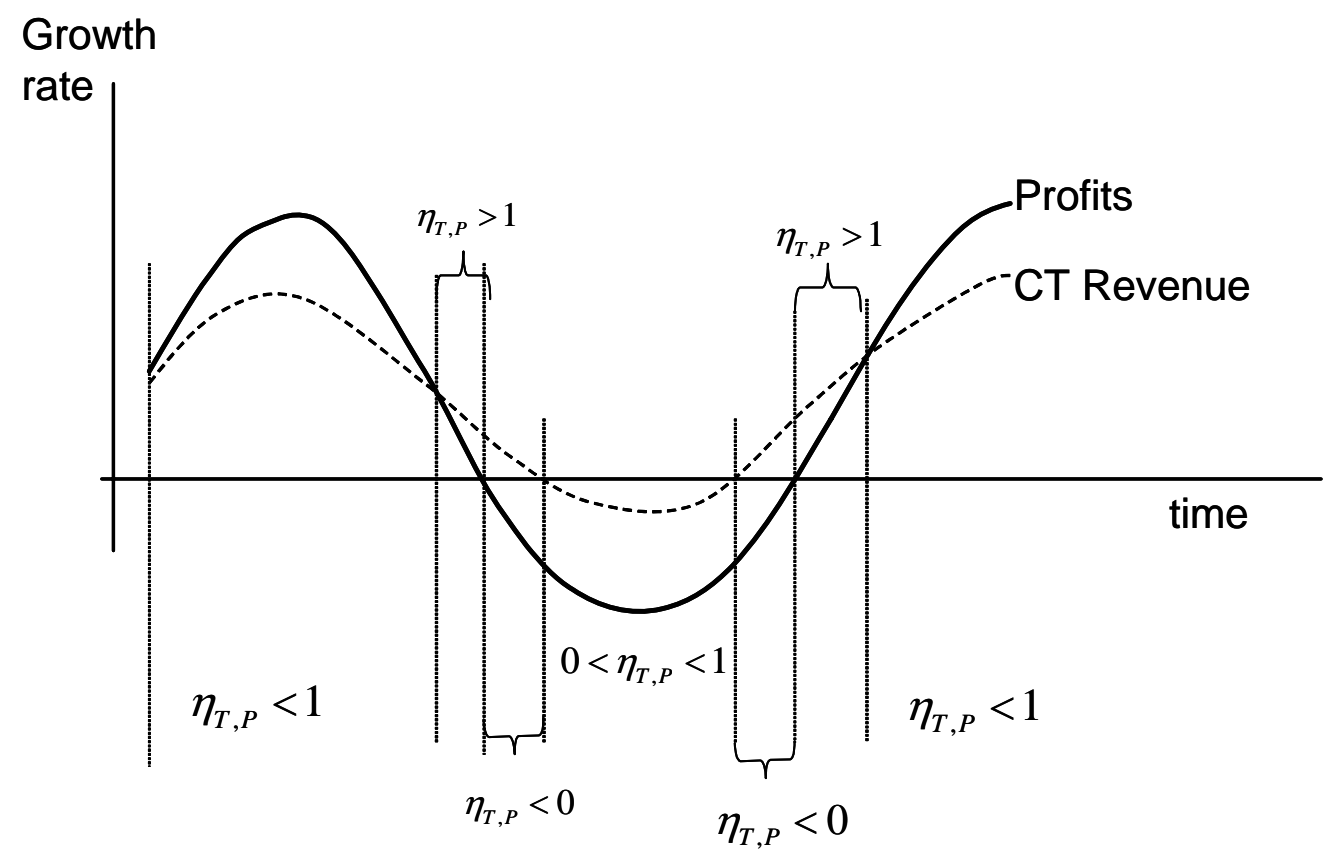

Figure 9: A Cycle with Negative Profit and Tax Growth

It is clear from these illustrative diagrams that the revenue elasticity can be highly volatile over the cycle, especially during economic downturns. In the case where only profit growth becomes negative in a downturn, the revenue elasticity can take large negative values, as well as relatively large positive values either side of the downturn. When tax growth can also become negative, it can be seen in Figure 11 that negative revenue elasticities are smaller and much less persistent but large positive elasticities are possible going into a downturn. These highly volatile revenue elasticities are of course obtained using a regular smooth cycle for profits and taxes, suggesting that with more erratic profit growth rates, revenue elasticities are likely to be even more volatile.

\section{Conclusions}

This paper began by considering the buoyancy of corporation tax receipts and accruals in the UK in recent years. Buoyancy measures the growth 


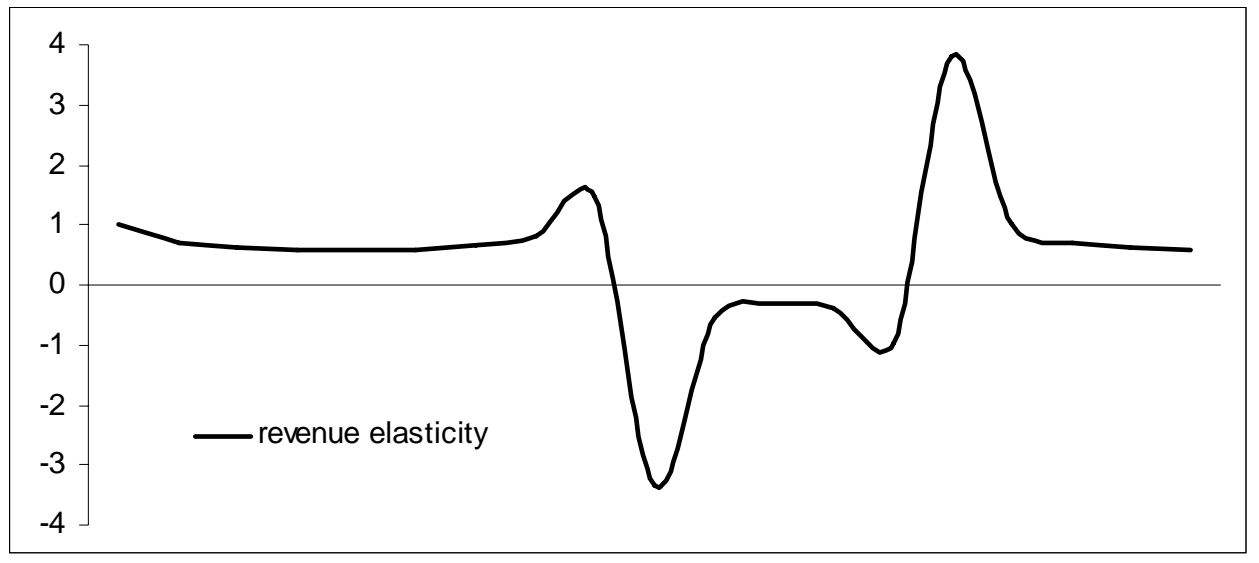

Figure 10: Elasticity with Negative Minimum Profit Growth

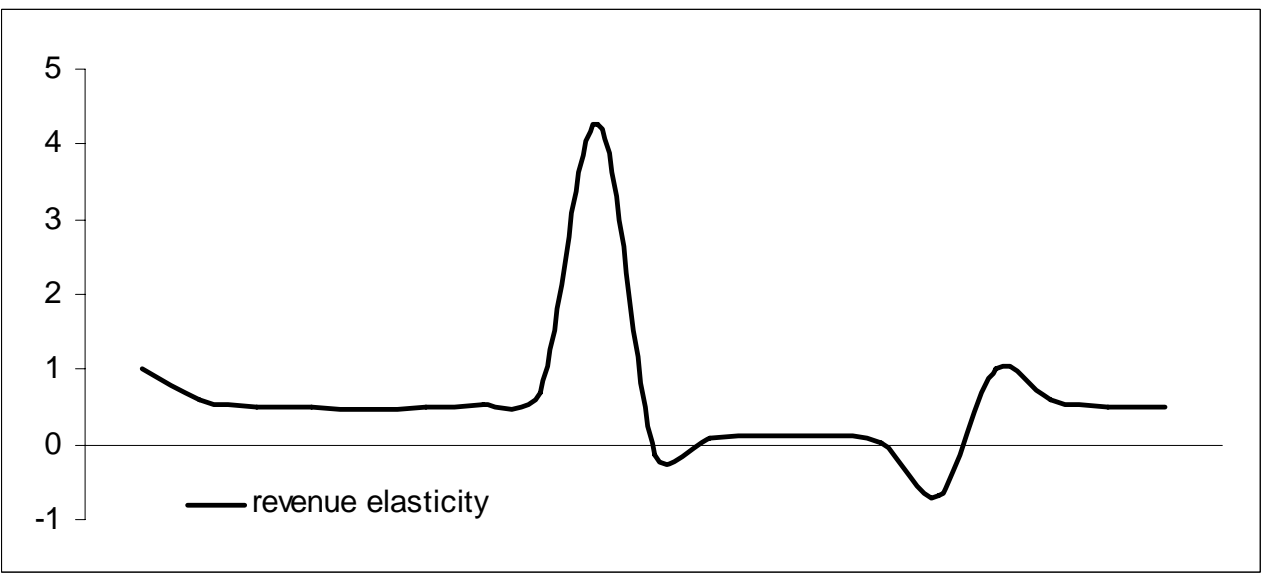

Figure 11: Elasticity with Negative Minimum Profit and Tax Growth 
in revenues as a ratio of the growth in profits, or GDP. This ratio is highly volatile from year to year. The paper then considered whether such volatility could be a feature of the inherent or 'fiscal drag' properties of the UK's corporation tax system. To measure fiscal drag - describing the way tax revenues grow relative to profits for an unchanged tax regime - the paper used the tax revenue elasticity measure. Section 4 provided a discussion of the conceptual issues involved in assessing the corporation tax revenue elasticity. This showed that deductions, and how they change as profits grow, play a crucial role in determining whether corporation tax revenues are expected to grow faster or slower than profits. Additionally for small firms, the nature of the corporate tax schedule - the tax rates and thresholds applied to net profits - can be important for such firms' revenue elasticities.

The analysis highlighted the role of cyclical factors. An important aspect for modelling to focus on is when, and to what extent, the corporation tax revenue elasticity deviates from its expected long-run value of 1 , when tax and profits grow at the same rate. Conceptual analysis and simulations suggests a number of conclusions.

First, the volatility observed in corporation tax buoyancy is also found to characterise the corporation tax revenue elasticity. Second, this implies that much of the observed volatility in corporation tax receipts and accruals could indeed be inherent to the corporation tax system, given the volatility in the tax base, profits.

Third, in mild economic downturns, corporation tax revenue elasticities may rise (because tax growth falls less than profit growth), but in more severe downturns, large but temporary increases and decreases in the revenue elasticity (and even negative elasticities) can be expected. Fourth, over the long-run (of one or more full economic cycles), corporation tax revenues and profits can be expected to grow at around the same rate (in the absense of discretionary changes in tax rates, compliance and so on). That is, the long-run revenue elasticity is likely to be around one. However, where there is shortrun volatility, annual averages of revenue elasticities would be a misleading guide to long-run tax growth.

These findings have serious implications for attempts to forecast corpo- 
ration tax revenue. Experience has shown that corporation taxes are among the most difficult to forecast, using conventional methods based, for example, on regressions of taxes and profits over time. Such regressions, using lag structures and observations over a long time period, may be able to approximate the long-run buoyancy of corporation taxes, and limited cyclical aspects. ${ }^{18}$ However their inability to capture discretionary tax changes mean they cannot distinguish the ceteris paribus effects of the revenue elasticity. In addition, they tyically cannot account for the highly volatile dimension of annual CT revenues which is captured in the modelling above. The analysis in this paper suggests that forecasting corporation tax revenues is likely to be especially difficult during pronounced economic downturns, but can be expected to be less problematic for above-trend fluctuations when corporate losses are less prevalent.

\footnotetext{
${ }^{18}$ For example, applying the HMRC/ONS tax and profit data used in Figure 2 to a simple log-log regression of tax revenue on profits, over the period 1978-2004, produces a long-run buoyancy parameter (the coefficient on log profits) of 1.1. With cyclical volatility, such parameter estimates can depend, of course, on the start/end date. For example, an equivalent regression over 1984-2004 yields a parameter of 0.92 .
} 


\section{Appendix: Gross and Net Profits for Single Firms}

This appendix provides an illustration of the behaviour of a firm's gross and net taxable profits in the presence of a regular cycle. Consider a single firm with a single profit source. In the UK corporation tax system, any losses incurred can be deducted against future profits when these return to positive values. ${ }^{19}$ The illustration below assumes that these are claimed at the earliest available opportunity. Positive profits are assumed to be taxed at a single rate (hence tax libaility is simply equal to net profits multiplied by the tax rate), while the tax rate on losses is zero.

Figure 12 shows the cyclical behaviour of gross and net profits if gross profits are assumed to follow a sine wave with an amplitude of 20 units around a constant trend level of 5 units. This produces positive gross profits of 25 units at the top of the cycle and gross profits (losses) of -15 units at the bottom of the cycle. The areas labelled A represent periods of gross loss while the areas labelled B (equal in size to A) represent the use of those losses to offset subsequent positive gross profits. It is clear from the Figure that net profits (and hence tax liabilities) follow a 'smoothed' cycle compared with gross profits.

\footnotetext{
${ }^{19}$ For some sources of profit in the UK, losses can alternatively be carried back one year to offset profits from the same source. This complication is ignored here.
} 


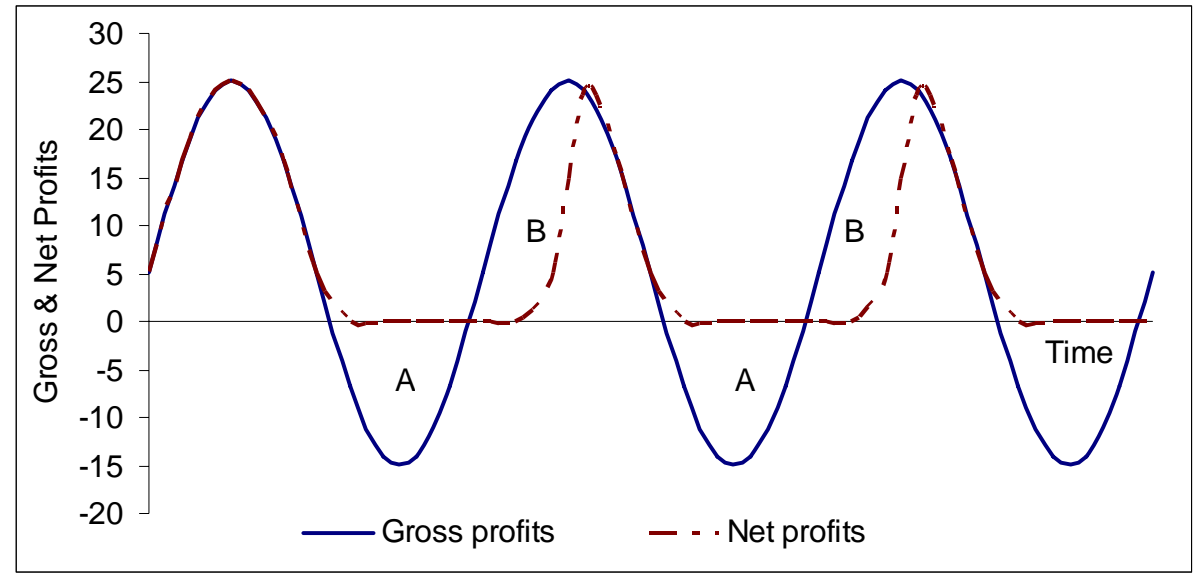

Figure 12: Simulating Gross \& Net Profit Cycles

\section{References}

[1] Basu, S., Emmerson, C. and Frayne, C. (2003) An Examination of the IFS corporation tax forecasting record. Institute for Fiscal Studies Working Paper, wp03/21. London: Institute for Fiscal Studies.

[2] Creedy, J. and Gemmell, N. (2002a) The revenue responsiveness of consumption taxes. Economic Record, 78, pp. 186-194.

[3] Creedy, J. and Gemmell, N. (2002b) The built-in flexibility of income and consumption taxes. Journal of Economic Surveys, 14, pp. 509-532.

[4] Creedy, J. and Gemmell, N. (2004) The revenue responsiveness of income and consumption taxes in the UK. Fiscal Studies, 25, pp. 55-77.

[5] Creedy, J. and Gemmell, N. (2006a) Modelling Tax Revenue Growth. Cheltenham: Edward Elgar.

[6] Creedy, J. and Gemmell, N. (2006b) A Microsimulation Model of UK Corporation Tax Revenues. A Report to HMRC.

[7] Devereux, M.P. and Klemm, A. (2003) Measuring taxes on income from capital: evidence from the UK. Institute for Fiscal Studies Working Paper, wp03/03. London: Institute for Fiscal Studies. 
[8] Devereux, M.P., Griffith, R. and Klemm, A (2004) How has the UK corporation tax raised so much revenue? Fiscal Studies, 25, pp. 367388.

[9] Heinemann, F. (2001) After the death of inflation: will fiscal drag survive? Fiscal Studies, 22, pp. 527-546.

[10] Metz, R. and Weale, M. (2003) Modelling corporation tax. (Unpublished paper). London: National Institute of Economic and Social Research.

[11] National Statistics (2005) The United Kingdom National Accounts. The Blue Book. Basingstoke: Palgrave Macmillan.

[12] Nicodeme, G. (2001) Computing effective corporate tax rates: comparisons and results. European Union Commission Economic Paper, no. 153 (D.G.Ec.Fin.).

[13] Young, G. (1992). A new approach to modelling corporation tax. $N a$ tional Institute Economic Review, 140, pp. 98-105. 